\title{
Positive pressure ventilation and cranial volume in newborn infants
}

\author{
DAVID W A MILLIGAN
}

Research Institute, Hospital for Sick Children, Toronto

SUMMARY The relationship between changes in airways pressure, pleural pressure, and cranial volume was studied in a group of sick newborn infants requiring ventilatory assistance. Cranial volume increased appreciably only when lung compliance was such that more than $20 \%$ of the applied airways pressure was transmitted to the pleural space, or if the absolute pleural pressure was greater than $4 \mathrm{cmH}_{2} \mathrm{O}$ above atmospheric pressure. The findings stress the need for more-critical monitoring during periods of rapid change in lung compliance.

The widespread use of positive end expiratory pressure $^{1}$ has been associated with an improvement in the outlook for infants with hyaline membrane disease (HMD). Many such infants still die or suffer long-term neurological sequelae as a result of intracranial haemorrhage. ${ }^{2}$ Although there is no known single cause for the haemorrhage, it is likely that the fragile vessel architecture in the subependymal layer of the germinal matrix is vulnerable to changes in cerebral arterial or venous pressure especially if there has been a preceding period of hypoxia which has compromised the integrity of the vessel walls, or if there is concurrent derangement of blood gas tensions. ${ }^{245}$ In addition control of autoregulation is impaired ${ }^{6}$ allowing central pressure changes to be transmitted to the cerebral vasculature. It has been suggested ${ }^{8}$ that a contributing factor may be the continuous level of positive airways pressure to which these infants are often exposed which may increase cranial venous volume and pressure by obstructing venous return to the right heart. In order to assess whether this was of concern a group of sick newborn infants was studied so that the relationship between cranial volume, airways pressure, and pleural pressure could be defined.

\section{Materials and methods}

Satisfactory measurements were obtained from 15 infants requiring ventilatory assistance. Seven had classical HMD, 3 had evidence of lung oedema on $x$-ray films (fluid in fissures, Kerley's B lines), 1 had

Table Clinical data and results of tests on 15 infants*

\begin{tabular}{|c|c|c|c|c|c|c|c|c|c|}
\hline Case & $\begin{array}{l}\text { Gestational } \\
\text { age } \\
\text { (weeks) }\end{array}$ & $\begin{array}{l}\text { Birthweight } \\
(g)\end{array}$ & $\begin{array}{l}\text { Age } \\
\text { (da.vs) }\end{array}$ & Diagnosis & $\begin{array}{l}C B F \text { index } \\
\mathrm{ml} / \mathrm{min} \text { per } \\
100 \mathrm{~g} \text { brain }\end{array}$ & $\begin{array}{l}\text { Peak airways } \\
\text { pressure } \\
\left(\mathrm{cmH}_{2} \mathrm{O}\right)\end{array}$ & $\begin{array}{l}\text { Peak pleural } \\
\text { pressure } \\
\left(\mathrm{CmH}_{2} \mathrm{O}\right)\end{array}$ & $\begin{array}{l}P P: A P \dagger \\
\text { ratio } \\
(\%)\end{array}$ & $\begin{array}{l}\text { Skull volume } \\
\text { change }(\%)\end{array}$ \\
\hline 1 & 30 & 1010 & $2 \cdot 3$ & HMD & & 28 & 1 & 10 & $\mathbf{0}$ \\
\hline 2 & 31 & 1220 & $1 \cdot 2$ & HMD & & 17 & 2 & 12 & 0.01 \\
\hline $3 \mathbf{a}$ & 31 & 1840 & 0.5 & HMD & 39 & 30 & 2 & 7 & 0 \\
\hline $3 b$ & 31 & 1840 & $1 \cdot 6$ & HMD & & 20 & 2 & 8 & 0.02 \\
\hline 4 & 32 & 1420 & 1.9 & HMD & 45 & 27 & 1 & 4 & 0.05 \\
\hline 5 & 33 & 1810 & $4 \cdot 3$ & HMD & & 30 & 2 & 7 & 0.05 \\
\hline 6 & 36 & 2490 & 0.6 & HMD & & 31 & 3 & 10 & 0.06 \\
\hline 7 & 36 & 2450 & $5 \cdot 6$ & HMD & & 20 & $1 \cdot 5$ & 7 & 0.01 \\
\hline 8 & 28 & 1430 & $1 \cdot 2$ & Lung oedema & 67 & 20 & 2 & 10 & 0.05 \\
\hline 9 & 35 & 2110 & $4 \cdot 9$ & Lung oedema & 43 & 16 & $\overline{2}$ & 12 & 0.04 \\
\hline 10 & 35 & 2320 & $2 \cdot 0$ & Lung oedema & 54 & 19 & 3 & 16 & 0.06 \\
\hline 11 & 30 & 1430 & $9 \cdot 1$ & PDA & 19 & 26 & 6 & 23 & 0.04 \\
\hline 12 & 30 & 1280 & 0.9 & Apnoea & 30 & 22 & 5 & 23 & $0 \cdot 15$ \\
\hline 13 & 37 & 2520 & $1 \cdot 3$ & Apnoea & & 20 & 6 & 30 & $0 \cdot 14$ \\
\hline 14 & 37 & 1820 & $1 \cdot 2$ & Asphyxia & 36 & 24 & $9 \cdot 5$ & 40 & $0 \cdot 34$ \\
\hline 15 & 38 & 1525 & $2 \cdot 7$ & Congenital rubella & & 13 & 6 & 51 & $0 \cdot 29$ \\
\hline
\end{tabular}

*All pressures are expressed as absolute values in relation to atmospheric pressure.

+ Pleural pressure/airways pressure \%

$\mathrm{CBF}=$ cerebral blood flow; HMD = hyaline membrane disease; PDA = patent ductus arteriosus 
increased pulmonary vascularity associated with a patent ductus arteriosus, and 4 infants had lungs that were nearly normal and were being ventilated for central apnoea. Details of the infants are shown in the Table. The infants were studied with minimal handling in the isolette. Pleural pressure was recorded from a latex balloon attached to a 5 FG feeding tube placed in the mid-oesophagus and attached to a Validyne DP7 pressure transducer. Airways pressure was measured at the T-junction of the endotracheal tube connection using a Statham PM 131 transducer. Changes in cranial volume were calculated from changes in occipito-frontal head circumference measured with a mercury-in-Silastic* strain gauge ${ }^{9}$ without jugular venous occlusion. Two sizes of gauge were used. For infants $<2 \mathrm{~kg}$ a 2 -strand $20 \mathrm{~cm}$ length of tubing (inside diameter $0 \cdot 6$, external diameter $1.17 \mathrm{~mm}$ ), for infants $>2 \mathrm{~kg}$ a 4-strand $60 \mathrm{~cm}$ length of tubing (inside diameter 0.75 , external diameter $1.6 \mathrm{~mm}$ ) was used. The justification for use of this method is discussed below. Where possible, aortic blood pressure (using a Bentley Trantec transducer) and transcutaneous $\mathrm{Po}_{2}$ (using a Radiometer TCM1 or Litton SM361 electrode) were measured at the same time.

All infants were awake or in rapid eye movement sleep during the study ${ }^{10}$ and no infant was studied within an hour of the preceding feed. ${ }^{11}$ Output was on 4-channel recording paper. Cerebral blood flow was measured in 8 infants using the method described by Cross et al. ${ }^{9}$

After a period of stabilisation a baseline pattern was recorded. The airways pressure waveform was then manipulated to assess the effects on skull volume. Three basic manoeuvres were attempted: stopping intermittent mandatory ventilation (IMV), alteration of positive end expiratory pressure (PEEP) level, and a change from IMV to assisted ventilation, or vice versa. Any manoeuvre was immediately stopped if the infant showed any sign of an adverse response. Tracings were examined by eye. Experiments were discounted if the level of movement was unacceptable or if balloon placement was unsatisfactory.

\section{Results}

Changes in occipito-frontal circumference as measured by a strain gauge closely reflect the accompanying changes in cranial volume. Fig. 1 shows a comparison of calculated versus actual volume changes in 5 infants who had varying quantities of cerebrospinal fluid removed for therapeutic purposes. The volumes correspond very

*Dow Corning Silicone Rubber.

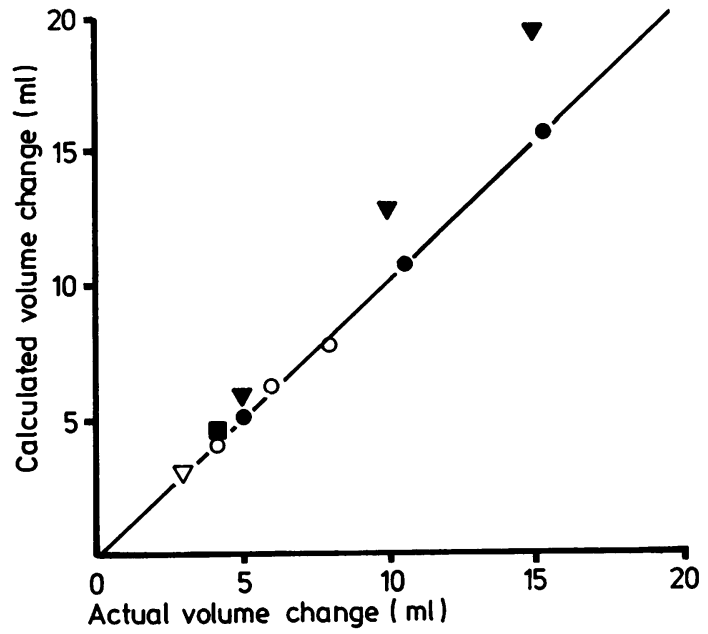

Fig. 1 Calculated skull volume change (vertical axis) compared with actual volume of cerebrospinal fluid removed (horizontal axis) in 5 infants. The same symbol refers to different volumes in the same infant. Solid line is line of identity, $r 0.974, P<0.001$.

closely when a conversion formula of volume $=$ circumference $^{3} / 89$ is used. ${ }^{9}$ Cerebrospinal fluid pressure changes are also closely parallel to changes in head circumference, as can be seen in Fig. 2 which shows a simultaneous recording of changes in ventricular pressure and head circumference during internal jugular venous occlusion in an infant with an exteriorised ventricular shunt.

The clinical data and results of the study for each infant are summarised in the Table. A consistent

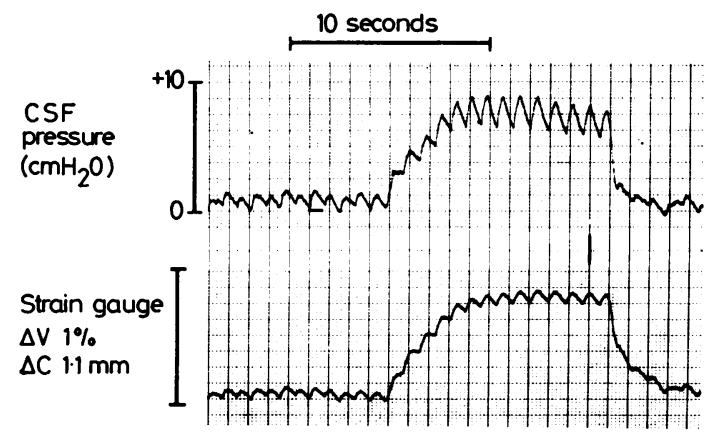

Fig. 2 Simultaneous tracing of cerebrospinal fluid pressure (upper trace) and occipito-frontal circumference measured by strain gauge (lower trace) during bilateral internal jugular venous occlusion. $\triangle C$ shows the calibration in terms of actual change in occipitofrontal circumference, and $\Delta V$ as a percentage change in skull volume. 
relationship was shown between the amount of skull volume expansion (expressed as a percentage of the resting volume) and the proportion of applied airways pressure which was transmitted to the pleural space. If the lungs were uncompliant, as judged by poor transmission of applied pressure, there was little or no change in cranial volume with each application of positive pressure. In infants with more-compliant lungs changes in airways pressure were associated with appreciable changes in cranial volume (Fig. 3). This is in direct contrast to the normal situation where each spontaneous inspiration is accompanied by a negative intrathoracic pressure which, in turn, is reflected in a decrease in cranial volume and intracranial pressure. The amount by which cranial volume increased was closely related to the proportion of applied airways pressure which was transmitted through to the pleural space (Fig. 4). The horizontal axis in Fig. 4 is an indirect measure of compliance so that those infants with more-compliant lungs had a greater increase in cranial volume for any given pressure applied at the airways. Fig. 5 illustrates the same relationship in terms of absolute pleural pressure.

There was a gradual increase in the maximal cranial volume change observed from the group with HMD

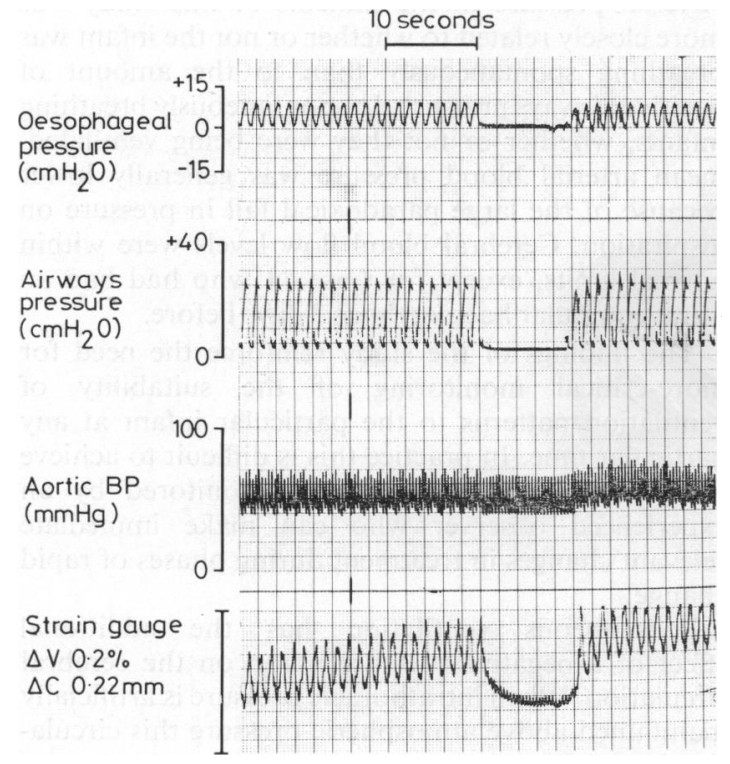

Fig. 3 Effects of stopping positive pressure ventilation on pleural pressure, arterial blood pressure, and crinial volume in an apnoeic infant (Case 13) with moderately compliant lungs. The cranial volume trace is at high gain for clarity.

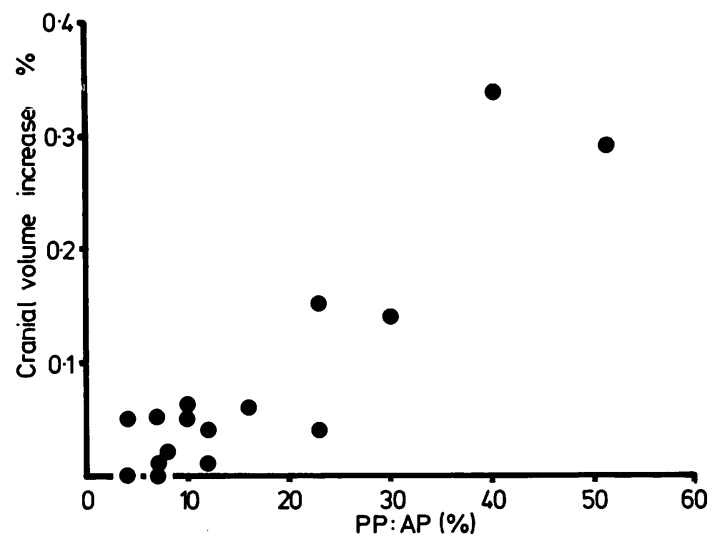

Fig. 4 Change in cranial volume (vertical axis) plotted against the proportion of applied airways pressure transmitted to the pleural space $(P P: A P)$ expressed as a percentage $r 0.909, P<0.001$.

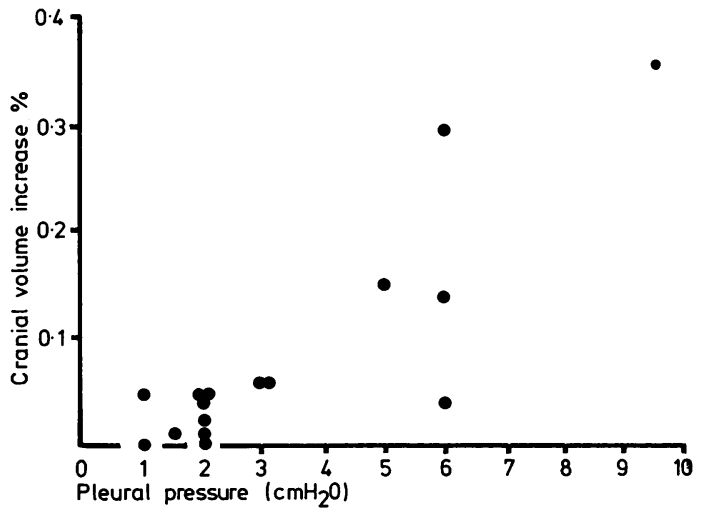

Fig. 5 Change in cranial volume (vertical axis) plotted against pleural pressure. The symbol at intercept 0.4,6 is Case 11 who had sustained an intraventricular haemorrhage 3 days previously and presumably had a stiff brain.

(mean $0.025 \%$, SD 0.024 ), through the group with lung oedema (mean $0.045 \%$, SD 0.01 ), to the group with apnoea (mean $0 \cdot 23 \%$, SD $0 \cdot 1$ ). There were significant differences between the apnoeic group and the group with HMD ( $\mathrm{P}<0.001$ by 2 -tailed $t$ test), and between the apnoeic group and the group with lung oedema $(\mathrm{P}<0.02$ by 2 -tailed $t$ test). There was no consistent difference between the maximum volume change observed in infants on IMV and those on assisted ventilation except that, if the IMV rate was not tailored to the infant's spontaneous rate, there were larger volume increases if spontaneous expiration occurred during ventilator inspiration. 


\section{Discussion}

It can be argued whether the ideal measurement for this study is of cranial venous pressure or cranial venous volume. A change in both pressure and volume generally occurs simultaneously although there may be a period of time during which venous capacitance vessels are filled before a rise in pressure takes place. This would suggest that a measurement of volume change should be more sensitive to early changes in the haemodynamic equilibrium. The evidence (Figs 1 and 2) shows that the non-invasive measurement of skull circumference changes accurately reflects changes in cranial volume and is a good proportional index of changes in intracranial pressure.

There are no figures available for cerebral blood volume in the newborn infant but, if it is of the same order as the 3-7 ml/100 $\mathrm{g}$ brain reported for adult $\operatorname{man}^{12-15}$ and a figure of $5 \mathrm{ml} / 100 \mathrm{~g}$ brain is used, the changes in cranial volume reported here would range from 0 to $8 \%$ of cerebral blood volume. Using a skull-brain compliance derived from Fig. 2 this would correspond to a range of pressure changes of from 0 to $3 \mathrm{cmH}_{2} \mathrm{O}$.

Many comments have been made about the potentially harmful effects of positive airways pressure on the circulation. ${ }^{16-19}$ Aidinis et al. ${ }^{20}$ studied the relationship between intracranial pressure, cerebral perfusion pressure, and level of applied PEEP in cats before and after embolisation of the lungs with oleic acid. They found significantly smaller increases in intracranial pressure and smaller reductions in cerebral perfusion pressure after oleic acid embolisation suggesting that the decreased lung compliance in such cases might have attenuated transmission of applied pressure to the great veins of the thorax. Apuzzo et al. ${ }^{21}$ studied a group of adult patients with severe head trauma and 'normal' lungs and found that significant increases of intracranial pressure with PEEP only occurred in those patients who demonstrated an increased cerebral elastance (that is stiff brains). As the pressure change for a given volume change will clearly be greater when the brain is on the steep part of its pressure-volume curve, it is possible that changes in cranial venous volume took place in all their patients but that these only manifested as pressure changes in those with increased elastance. Cuypers et al..$^{22}$ found a rise in brain volume caused by vessel expansion in all cats exposed to raised levels of central venous pressure. Brain tissue pressure increased only transiently and congestive oedema did not occur unless the brain tissue was first damaged. The findings in the present study agree with those of Aidinis et al..$^{20}$ and suggest that infants with the most severe lung disease will be least at risk from transmission of airways pressure to the cerebral circulation. This does not imply that the danger of positive pressure should be ignored. It is likely that the most dangerous situations arise if lung compliance increases rapidly over a short period of time. This characteristically occurs during the first few breaths after birth and in the recovery phase of HMD. Over-enthusiastic resuscitation in the delivery room is potentially as harmful in this respect as inadequate tailoring of ventilator pressures to the rapidly changing lung compliance in the recovery phase of HMD. In both situations significant increases in cranial volume could occur, setting the stage for a haemorrhage.

It is not known what constitutes a 'significant' alteration in cerebral blood volume but it could reasonably be assumed that any increase outside normal levels will be associated with some degree of venous congestion and that the greater the venous congestion the higher the possibility of vessel rupture. Cerebral blood flow is not likely to fall until high levels of intracranial pressure are reached ${ }^{2324}$ unless perfusion pressure falls at the same time. Falls in arterial blood pressure have often been noted with the use of PEEP ${ }^{16-18}$ and will depend on the amount of airways pressure transmitted. If myocardial function is impaired ${ }^{25}$ the effect will be exaggerated. Arterial pressure in the patients in this study was more closely related to whether or not the infant was breathing spontaneously than to the amount of positive airways pressure. In spontaneously breathing infants, whether or not they were being ventilated, mean arterial blood pressure was generally lower because of the large paradoxical fall in pressure on inspiration. Cerebral blood flow levels were within normal limits, except for Case 11 who had had an intraventricular haemorrhage 3 days before.

The findings of the study reinforce the need for more-critical monitoring of the suitability of ventilation patterns to the particular infant at any particular time. In practice this is difficult to achieve unless the infant is constantly monitored by an experienced observer who can make immediate relevant changes in treatment during phases of rapid change.

Spontaneous ventilation has the additional effect of a negative pressure pump on the cerebral circulation. When intrathoracic pressure is artificially maintained above atmospheric pressure this circulation is at risk.

I thank Dr M H Pryan, Dr A C Bryan, and Dr P M Fitzhardings for support and constructive criticism. 


\section{References}

1 Gregory G A, Kitterman J A, Phibbs R H, Tooley W H, Hamilton W K. Treatment of the idiopathic respiratorydistress syndrome with continuous positive airway pressure. N Engl J Med 1971 ; 284: 1333-40.

2 Volpe J J. Neonatal intracranial haemorrhage: pathophysiology, neuropathology, and clinical features. Clin Perinatol 1977; 4: 77-102.

3 Fitzhardinge P M, Kalman E, Ashby S, Pape K E. Present status of the infant of very low birthweight treated in a referral neonatal intensive care unit in 1974. In: Elliott K, O'Connor M, eds. Major mental handicap: methods and costs of prevention. Ciba Foundation Symposium 59. Amsterdam: Elsevier, 1978: 139-44.

4 Hambleton G, Wigglesworth J S. Origin of intraventricular haemorrhage in the preterm infant. Arch Dis Child 1976; 51: 651-9.

5 Towbin A. Cerebral intraventricular haemorrhage and subependymal matrix infarction in the fetus and premature infant. Am J Pathol 1968; 52: 121-39.

6 Lou H C, Lassen N A, Friis-Hansen B. Impaired autoregulation of cerebral blood flow in the distressed newborn infant. J Pediatr 1979; 94: 118-21.

7 Milligan D W A. Failure of autoregulation and intraventricular haemorrhage in preterm infants. Lancet 1980 ; i: 896-8.

8 de Lemos R A, Tomasovic J J. Effects of positive pressure ventilation on cerebral blood flow in the newborn infant. Clin Perinatol 1978; 5 : 395-409.

9 Cross K W, Dear P R F, Hathorn M K S, et al. An estimation of intracranial blood flow in the newborn infant. J Physiol 1979; 289: 329-45.

10 Milligan D W A. Cerebral blood flow and sleep state in the normal newborn infant. Early Hum Dev 1979; 3: 321-8.

11 Dear P R F. Effect of feeding on jugular venous blood flow in the normal newborn infant. Arch Dis Child 1980; 55: $365-70$.

12 Nylin G, Hedlund S, Regnström O. Studies of the cerebral circulation with labelled red cells in healthy man. Circ Res 1961 ; 9: 664-74.

13 Matthew N J, Meyer J S, Bell R L, Johnson P C, Neblett C R. Regional cerebral blood flow and blood volume measured with the gamma camera. Neuroradiology $1972 ; 4: 133-40$.
14 Ladurner G, Zilkha E, Iliff L D, DuBoulay G H, Marshall J. Measurement of regional cerebral blood volume by computerized axial tomography. J Neurol Neurosurg Psychiatry 1976; 39: 152-8.

15 Greenberg J H, Alavi A, Reivich M, Kuhl D, Uzzell B. Local cerebral blood volume response to carbon dioxide in man. Circ Res 1978; 43: 324-31.

16 Colgan F J, Barrow R E, Fanning G L. Constant positivepressure breathing and cardiorespiratory function. Anesthesiology 1971; 34: 145-51.

17 de Lemos R A, McLaughlin G W, Robison E J, Schulz J, Kirby $R \mathbf{R}$. Continuous positive airway pressure as an adjunct to mechanical ventilation in the newborn with respiratory distress syndrome. Anesth Analg (Cleve) 1973; 52: 328-32.

18 Powers S R, Jr, Mannal R, Neclerio M, et al. Physiologic consequences of positive end-expiratory pressure (PEEP) ventilation. Ann Surg 1973;178: 265-72.

10 Scharf S M, Caldini P, Ingram R H, Jr. Cardiovascular effects of increasing airway pressure in the dog. Am J Physiol 1977; 232: H35-43.

20 Aidinis S J, Lafferty J, Shapiro H M. Intracranial responses to PEEP. Anesthesiology 1976; 45: 275-86.

21 Apuzzo M L J, Weiss M H, Petersons V, Small R B, Kurze T, Heiden J S. Effect of positive end expiratory pressure ventilation on intracranial pressure in man. $J$ Neurosurg 1977; 46: 227-32.

22 Cuypers J, Matakas F, Potolicchio S J, Jr. Effects of central venous pressure on brain tissue pressure and brain volume. J Neurosurg 1976; 45: 89-94.

23 Kety S S, Shenkin H A, Schmidt C F. The effects of increased intracranial pressure on cerebral circulatory functions in man. J Clin Invest 1948; 27 : 493-9.

24 Häggendal E, Löfgren J, Nilsson N J, Zwetnow N N. Effects of varied cerebrospinal fluid pressure on cerebral blood flow in dogs. Acta Physiol Scand 1970; 79: 262-71.

25 Finley J P, Howman-Giles R B, Gilday D L, Bloom K R, Rowe $R$ D. Transient myocardial ischemia of the newborn infant demonstrated by thallium myocardial imaging. J Pediatr 1979; 94: 263-70.

Correspondence to Dr D W A Milligan, Department of Paediatrics, University College Hospital, Huntley Street, London WC1E 6AU.

Received 27 February 1980 